\title{
CARLEMAN-KNOPP TYPE INEQUALITIES VIA HARDY INEQUALITIES
}

\author{
PANKAJ JAIN, LARS-ERIK PERSSON AND ANNA WEDESTIG
}

\begin{abstract}
Some new Carleman-Knopp type inequalities are proved as "end point" inequalities of modern forms of Hardy's inequalities. Both finite and infinite intervals are considered and both the cases $p \leqslant q$ and $q<p$ are investigated. The obtained results are compared with similar results in the literature and the sharpness of the constants is discussed for the power weight case. Moreover, some reversed Carleman-Knopp inequalities are derived and applied.
\end{abstract}

Mathematics subject classification (2000): 26D15, 26D07.

Key words and phrases: Inequalities, Hardy's inequality, Carleman's inequality, Knopp's inequality.

\section{REFERENCES}

[1] T. Carleman, Sur les fonctions quasi-analytiques, Conferences faites au cinquième congres des mathématiciens scandinaves (Helsingfors 1923), 181-196.

[2] P. DrÁBEK, H. P. HeINIG AND A. KUfNer, Higher dimensional Hardy inequality, International Series of Numer., Math. vol. 123, Birkhäuser, 1997.

[3] H. P. Heinig, R. Kerman and M. Krbec, Weighted exponential inequalities, Preprint No. 79(1992), Math. Inst. Acad. Sci. Prague.

[4] P. JAIN AND A. P. SINGH, A characterization for the boundedness of geometric mean operator, Applied Math. Letters, Vol. 13, No. 8 (2000), 63-67.

[5] P. JAIn, L. E. PERSSON AND A. WedESTIG, From Hardy to Carleman and general mean-type inequalities, Function Spaces and Applications, Narosa Publishing House, 2000, 117-130.

[6] A. M. JARRAH AND A. P. SingH, A limiting case of Hardy's inequality, Indian J. Math., to appear.

[7] K. KNopP, Über Reihen mit positiven Gliedern, J. London Math. Soc. 3(1928), 205-211.

[8] E. R. Love, Inequalities related to those of Hardy and of Carleman and Lee, Math. Proc. Camb. Phil. Soc., 99(1986), 395-408.

[9] E. R. Love, Inequalities related to Knopp's inequality, Math. Anal. Appl., 137 (1), (1990), 173-180.

[10] B. OpIC AND A. Kufner, Hardy-Type Inequalities, Pitman Research Notes in Mathematics Series, Vol. 211, Longman Scientific and Technical Harlow, 1990.

[11] B. OPIC AND P. GuRKA, Weighted inequalities for geometric means, Proc. Amer. Math. Soc. 3(1994), 771-779.

[12] B. G. PAChPATtE AND E. R. LOVE, On some new inequalities related to Hardy's integral inequality, Math. Anal. Appl., 149 (1), (1990), 17-25.

[13] L. PICK AND B. OPIC, On the geometric mean operator, J. Math. Anal. Appl. 183 (3), (1994), 652-662.

[14] G. H. HARdy, J. E. LitTlewoOd AND G. Pólya, Inequalities, University Press, Cambridge, 1964.

[15] J. PeEtre AND L. E. Persson, A general Beckenbach's inequality with applications, In: Function Spaces, Differential Operators and Nonlinear Analysis, Pitman Research Notes in Math. ser 211 (1989), $125-139$.

[16] L. E. PERSSON AND V. D. STEPANOV, Weighted integral inequalities with the geometric mean operator, J. of Inequal. \& Appl, to appear.

Research Report No. 9, Department of Mathematics, Luleå University of Technology, 2000.

[17] V. D. STEPANOV, The weighted Hardy's inequality for nonincreasing functions, Trans. Amer. Math. Soc., 338 (1), (1993), 173-186. 